\section{The nature of science}

SIR-While A. Travis (Nature 341, 10; 1989) may be bemused by the Universe, he is certainly befuddled about the nature of science. It would seem that, to Travis, only when a model can be "tested experimentally can it be held as truth". I, and I am sure many other scientists, would take issue with this statement.

Science cannot and should not claim to be discovering truths. As fallible human beings and scientists, our best hope is to propose theories (or hypotheses) that are rigorous enough to withstand repeated testing and to be supported by the evidence that can be gathered. Many of the theories simply will not withstand the testing and will either be falsified outright or, more likely, be replaced by a new and better corroborated theory. This is the strength of the so-called 'scientific method' in attempting to understand the world around us. It cannot proclaim ultimate truths as Travis would suggest, for those who do so step out of the realm of science.

A more debatable issue is whether only experimental science is truly science. Both the aforementioned statement of Travis and a later comment that "untestable theories in science (such as the evolution of life through random diversification followed by natural selection) are permissible, but not if they involve forces from an unknowable source", suggest that Travis would hold to the stricter 'experimentalist' perception of science. By most scientists'

\section{Sahni visit denied}

SIR-In normal circumstances, I would have ignored V. J. Gupta's statement (Nature 341, 11-12; 1989) that my father, the late M. P. Sahni, had visited his (Gupta's) localities in 1964, as not being central to the main issues at stake in the matter of the 'peripatetic fossils' - see the article by Talent (Nature 338, 613-615; 1989) and those by others (Nature 341, $13-16 ; 1989)$. But the present situation is far from normal and warrants that the truth be made known regarding $M$. P. Sahni's involvement in the matter. Sahni had an unblemished and distinguished record of meticulously conducted research spanning nearly half a century. It is therefore all the more distressing that his name has been dragged into a controversy after his death, and this has provoked several of his friends, ex-colleagues and well-wishers to ask me to set the record straight.

The facts are that Sahni attended a seminar at Srinagar (Jammu and Kashmir) in October 1964. He left Srinagar on 16 October, seen off at the airport by Dr S.K. Shah, one of the organizers of that seminar and now professor of geology at the University of Jammu. During his brief perception of their profession, however, if a theory is untestable it is not science and is not permissible, at least within the realm of science. The statement only makes sense if one replaces "untestable" with "non-experimental". If this is done, I have less quibble with the statement, because much of testable science is in fact nonexperimental. Every science, but some more than others, has an historical component that represents a unique series of events that took place in the near or very distant past. The experiment has been run, but the evidence is there and can be corroborated over and over again just as an experiment can hopefully be repeated.

J. DAVID ARCHIBALD

Biology Department,

San Diego State University,

San Diego, California 92182, USA

SIR-A. Travis feels compelled to invoke a 'creative force' when considering the mysteries of the observable Universe, in particular those aspects that appear least amenable to scientific investigation. I doubt, however, whether it is appropriate to label such areas of mystery as being particularly 'religious'. Such labelling is similar to that which became popular following the deistic movement of the early eighteenth century, in which 'god' or 'religion' were invoked to explain phenomena for which science had not yet found satisfactory theories. Not surprisingly, such a 'god-of-the-gaps' faded like the

halt, Sahni neither visited the graptolite localities nor did he accompany the postseminar field excursion and I have documentary evidence to substantiate this.

The controversy over the "peripatetic fossils' has caused intense introspection and soul-searching among Indian earth scientists in general and palaeontologists in particular. Open systems based on trust are fragile institutions prone to attack, but the strength of such systems derives from the internal reaction and response in the hour of crisis. By this yardstick, the national response has been spontaneous and extensive: exposure in the news media and the setting up of two major commissions of inquiry and other bodies of investigation. Introspection has led to action.

Centre of Advanced Studies in Geology,

Panjab University,

Chandigarh - 160014, India

- In the article by U. K. Bassi (Nature 341, $15-16 ; 1989)$ the author's institutional address was used in error. Although U.K. Bassi can be contacted at the Geological Survey of India, his personal address should have appeared in the article. smile on the Cheshire cat as science continued its advance. The invoking of a 'creative force' to fill the present gaps in our scientific knowledge does not seem any more satisfactory. The task of science is to construct better and better 'maps' that will incorporate an increasingly sophisticated understanding of the world around us, and there is no reason to suppose that topics such as 'human intelligence' and the 'origin of life' will not be much better defined in future maps than they are on the rather poor ones that we have at present.

Those who laid the foundations of modern science in the seventeenth century did not look for gaps in their scientific knowledge in which to make room for their religious beliefs. Quite the reverse: they saw behind the complete 'map' of scientific knowledge a God whose continuing creative activity made it a worthwhile enterprise to look for consistency and reproducibility in physical phenomena in the first place. Their sense of awe at the world around them came not so much from its unexplained mysteries as from the fact that it was explicable, and could be expressed particularly in the language of mathematics. For example, Galileo saw God as the "divine mathematician", who had made a universe that was intelligible by the human mind, so that investigating "the true constitution of the universe" was "the most important and most admirable problem that there is"'. Three hundred years later, our investigations of the 'true constitution of the universe' have a very long way to go, but it is good to emphasize that religion, at least the kind of religion that Galileo espoused, still has no hidden investments in scientific ignorance. The role of religion and philosophy is to address the much broader questions of whether the very existence of the 'map' itself, with ourselves as part of it, has any particular meaning in a more ultimate sense, and also to tackle the vital ethical questions as to how our scientific knowledge should be used. Peter Medawar has recently reminded us that the scientific method itself is not equipped to provide answers for such questions ${ }^{2}$. But as we attempt to tackle them at other levels, the proposal of 'unknown, creative forces' as religious-sounding plugs for the gaps in our present scientific knowledge is as inappropriate for religion as it is for science.

\section{Cell Surface Biochemistry Laboratory, Imperial Cancer Research Fund Laboratories,}

PO Box 123 ,

Lincoln's Inn Fields,

London WC2A 3PX, UK 1. Drake, S (transl.) Discoveries and Opinions of Galileo
97 , (Doubleday-Anchor, Garden City, New York, 1957).
2. Medawar, P. The Limits of Science (Oxford University
Press, 1985).

NATURE - VOL $342 \cdot 23$ NOVEMBER 1989 